\title{
Synthesis of pinacols through electrochemical reduction of carbonyl compounds at platinum cathode in non-aqueous weakly acidic medium
}

\author{
K. L. Yadava, Sanjeev Kumar, Anupam Kumar and R. K. P. Singh" \\ Department of Chemistry, University of Allahabad, Allahabad-211 002, India \\ Manuscript received 23 .July 2003, revised 14 November 2003, accepted 12 .Junuary 2004
}

\begin{abstract}
The electrochemical reduction of $p$-methylacetophenone, $m$-nitrobenzaldehyde $p$-dimethylaminobenzaldehyde and $p$-hydroxybenzaldehyde was carried out at controlled potential in weakly acidic medium (phenol, $\mathrm{p} K_{\mathrm{i}}=9.98$ ) for the purpose of investigating this type of reduction as a possible synthetic procedure for the preparation of 1,2-diol (or pinacol). The products formed during clectrolysis at constant cathode potential are reported here.
\end{abstract}

In the present communication, we are reporting the result of our studies on the reduction of some carbonyl compounds specially aryl ketone and arylaldehyde viz. pmethylacetophenone, $m$-nitrobenzaldehyde, p-dimethylaminobenzaldehyde and $p$-hydroxybenzaldehyde. Constant potential electrolysis was carried out. At definite potential the electrode surface is covered by dark brownish layer of the reduction product and that very product is continually diffused in the bulk which is visible.

\section{Results and discussion}

The electrochemical reduction of carbonyl compounds in aqueous ethanol system is $\mathrm{pH}$ dependent and takes place with the intermediacy of corresponding free-radical carbinolate ion in the alkaline region and the radical carbinolate is formed in the acidic medium. The reduction to the carbinol of the resultant free radical and its ion possibly occurs before dimerisation!

But as per our experiment in non-aqueous weakly acidic (phenol. $\mathrm{p} K_{\mathrm{a}}=9.98$ ) medium no such pH-dependency is seen. In this experiment, the dimethylformamide (DMF) and weak acid (phenol) provides the good system $^{2}$, and phenol serves as a proton donor.

It is generally accepted that the behaviour of carbonyl compounds, in aqueous or non-aqueous systems, is determined by the availability of protons. In water and alcohol this can be measured by $\mathrm{pH}$ and controlled by buffers. In aprotic solvents, it can be controlled by addition of proton donors?.

Mechanism of carbonyl reduction involves a reversible one-electron reduction to form an anion radical, which in the absence of proton donors, can diffuse into the solution to dimerise. With sufficient proton-donor, the rate of protonation can be more rapid than the rate of diffusion ${ }^{4}$.

$$
\begin{aligned}
& \mathrm{R}_{2} \mathrm{C}=\mathrm{O}+e^{-} \rightarrow \mathrm{R}_{2} \dot{\mathrm{C}}-\mathrm{O}^{-} \\
& (\mathrm{A})+\mathrm{H}^{+} \rightarrow \mathrm{R}_{2} \dot{\mathrm{C}}-\mathrm{OH} \rightarrow \text { dimerise } \\
& (\mathrm{B})+e^{-} \rightarrow \mathrm{R}_{2} \mathrm{C}^{-}-\mathrm{OH}
\end{aligned}
$$

For constant-potential electrolysis, the conventional threeelectrode cell with platinum as working as well as counter electrode and saturated calomel electrode (SCE) as reference electrode was used.

In this case $0.1 M$ aqueous solution of $\mathrm{KCl}$ and phenol were used as supporting electrolyte as a proton-donor respectively.

\begin{tabular}{lcc}
\hline \multicolumn{3}{c}{ Table 1. Experimental conditions of electrolysis } \\
Starting & Solvent & Strength of the \\
material & used & solution \\
$p$-Methylacetophenone (colourless-liquid) & DMF & $5 \% \mathrm{v} / \mathrm{v}$ \\
$m$-Nitrobenzaldehyde (brownish solid) & DMF & $4 \% \mathrm{w} / \mathrm{v}$ \\
$p$-Dimethylaminobenzaldehyde & DMF & $4 \% \mathrm{w} / \mathrm{v}$ \\
(Brownish crystalline solid) & & \\
$p$-Hydroxybenzaldehyde & DMF & $4 \% \mathrm{w} / \mathrm{v}$ \\
(Brownish powdery solid) & & \\
\hline
\end{tabular}

All the electrolysis was carried out at their corresponding reduction potentials and were completed in $3 \mathrm{~h}$ (Table 2). After $3 \mathrm{~h}$ no reduction product was seen to diffuse in the bulk.

In each case the work involved extracting the non-aqueous solution with double-distilled water $(4 \times 100 \mathrm{ml})$. The reddish brown organic liquid obtained in case of $p$ methylacetophenone dark brownish organic liquid in case of $m$-nitrobenzaldehyde, blackish semi solid substance in case of $p$-dimethylaminobenzaldehyde and reddish brown coloured liquid in case of $p$-hydroxybenzaldehyde are entirely different from those of starting material. 


\begin{tabular}{|c|c|c|c|}
\hline \multicolumn{4}{|c|}{ In casc of p-methylacelophenone : } \\
\hline $\begin{array}{l}\text { Tinn } \\
\text { (h) }\end{array}$ & $\begin{array}{c}\text { Applied } \\
\text { potential (mV) }\end{array}$ & $\begin{array}{c}\text { Current in } \\
\mathrm{mA}\end{array}$ & $\begin{array}{l}\text { Yield } \\
(\%)\end{array}$ \\
\hline $0 .(00-0.30$ & $17(x)$ & 0.02 & \\
\hline $0.30-1.00$ & 1700 & 0.01 & \\
\hline $1.00-1.30$ & 1700 & 0.01 & $>90$ \\
\hline 1.3()$-2 .(x)$ & $17(x)$ & 0.01 & \\
\hline $2.0(1-2.30$ & 1700 & 0.01 & \\
\hline $2.30-3 .(x)$ & $17(x)$ & 0.02 & \\
\hline \multicolumn{4}{|c|}{ In ciase of m-nitrobenzaldehyde : } \\
\hline $0.00-0.30$ & $33(x)$ & 0.08 & \\
\hline $0.30-1.00$ & 3300 & 0.07 & \\
\hline $1.00-1.30$ & 3300 & 0.07 & \\
\hline $1.30-2 .(x)$ & 3300 & 0.06 & $>80$ \\
\hline $2 .(x)-2.30$ & $33(x)$ & 0.06 & \\
\hline $2.3(1-3.00$ & 3300 & 0.07 & \\
\hline \multicolumn{4}{|c|}{ In case of p-dimethylaminobenzaldehyde : } \\
\hline $0.0(0-0.30$ & 1700 & 0.03 & \\
\hline $0.30-1.00$ & 1700 & 0.03 & \\
\hline $1.0(1-1.30$ & 1700 & 0.04 & \\
\hline $1.30-2.00$ & 1700 & 0.05 & $>90$ \\
\hline $2 .(x)-2.30$ & $17(0)$ & 0.06 & \\
\hline $2.30-3.00$ & 1700 & 0.03 & \\
\hline \multicolumn{4}{|c|}{ In case of $p$-hydroxybenzaldehyde : } \\
\hline $0.00-0.30$ & 800 & 0.03 & \\
\hline$(0.30-1.00)$ & 800 & 0.04 & \\
\hline $1.00-1.30$ & 800 & 0.03 & \\
\hline $1.30-2 .(0)$ & $8(0)$ & 0.03 & $>90$ \\
\hline $2.002-2.30$ & 800 & 0.03 & \\
\hline $2.30-3.00$ & 800 & 0.03 & \\
\hline
\end{tabular}

Analyses of the products :

As per mechanism. following products are formed.

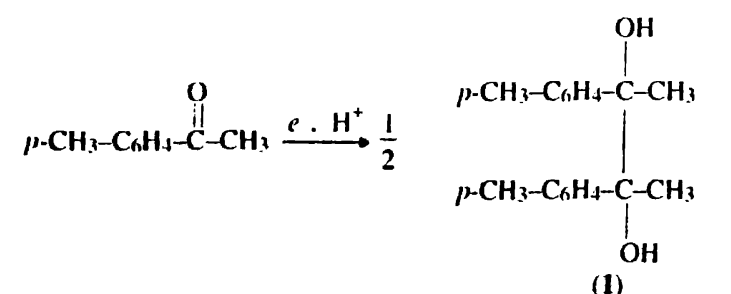

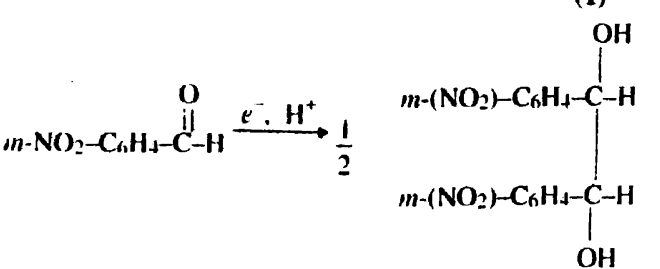

(2)

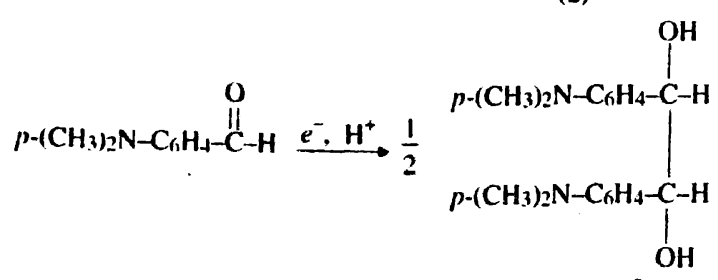

(3)

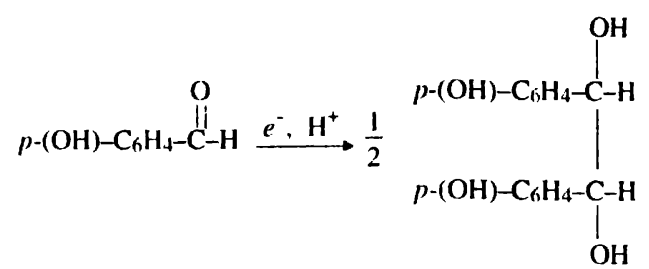

(4)

Starting materials give positive test of carbonyl functional group with 2,4-dinitrophenylhydrazine; whereas products are not responding the test of carbonyl functional group with the above reagent.

All the products were tested by the usual chemical ways and spectral analyses.

IR spectra of the products showed characteristic bands at $1400-1310$ and $1200-1125 \mathrm{~cm}^{-1} \mathrm{C}-\mathrm{O}$ stretching [tertiary alcohol in product (1)] and near $1100 \mathrm{~cm}^{-1}$ [secondary alcohol in product (2), (3) and (4)).

A peak at $1693 \mathrm{~cm}^{-1}(-\mathrm{C}=\mathrm{O})$ was observed in the starting material, which disappeared in the products.

A broad band at $3412.7 \mathrm{~cm}^{-1}$ [in product (1)], 3424.4 $\mathrm{cm}^{-1}$ [in product (2)], and $3398.5 \mathrm{~cm}^{-1}$ [in product (3)] due to $\mathrm{O}-\mathrm{H}$ (stretching) was seen, which suggests that the products are pinacols.

Pinacols are synthetically important compound. Using electrochemical technique pinacol synthesis became more important because this technique is a part of Green Chemistry i.e. it can be prepared without any environmental hazards.

\section{Experimental}

\section{Reaction mixture :}

$50 \mathrm{cc}$ of the non-aqueous solution of the starting material $+50 \mathrm{cc}$ of the $0.1 \mathrm{~N}$ aqueous solution of $\mathrm{KCl}+5 \mathrm{cc}$ phenol $\left(\mathrm{p} K_{\mathrm{i}}\right.$ 9.98).

$p$-Methylacetophenone, $m$-nitrobenzaldelyde, $p$-dimethylaminobenzaldehyde, p-hydroxybenzaldehyde, mercury, $\mathrm{KCl}$ and phenol were of AnalaR grade. Water used was double-distilled.

Controlled-potential electrolytic studies were carried out using three-electrode cell assembly having Pt-plate as working as well as counter electrode, and SCE as a reference-electrode; and four-necked reaction bottle (designed by our laboratory). Potential-cum-galvanostat was used for carrying out controlled-potential electrolysis.

\section{Acknowledgement}

The author's wish to thank Head of the Department of Chemistry for providing facilities and R.S.I.C. (a division of C.D.R.I., Lucknow) for recording spectra. 


\section{References}

I. S. R. Yadav. P. Goyal. A. Sharma, P. S. Verma and I. K. Sharma. I. Indian Chem. Soc., 2002. 79. 695.

2. P. H. Given and M F Peover I. Chem. Soc., 1960, 385.
3. C. K. Mann and K. K. Barnes. "Electrochemical Reactions in Nonaqueous Systems", Mared Dekker. New York, 1970, p. 180.

4. G. J. Hoijtink, J. Van. Schooten, E. de Bocr and W. I. Aalbersberg. Rec: Tran. Chim., 1954. 73. 355 